Research Article

\title{
Relationship between the Optical Properties and Chemical Composition of Urban Aerosol Particles in Lithuania
}

\author{
Julija Pauraite (D), Kristina Plauškaitè, Vadimas Dudoitis, and Vidmantas Ulevicius
}

SRI Center for Physical Sciences and Technology, Savanoriu Avenue 231, LT-02300 Vilnius, Lithuania

Correspondence should be addressed to Julija Pauraite; julija.pauraite@ftmc.lt

Received 31 May 2018; Revised 8 August 2018; Accepted 12 August 2018; Published 17 September 2018

Academic Editor: Alastair Williams

Copyright (C) 2018 Julija Pauraite et al. This is an open access article distributed under the Creative Commons Attribution License, which permits unrestricted use, distribution, and reproduction in any medium, provided the original work is properly cited.

\begin{abstract}
In situ investigation results of aerosol optical properties (absorption and scattering) and chemical composition at an urban background site in Lithuania (Vilnius) are presented. Investigation was performed in May-June 2017 using an aerosol chemical speciation monitor (ACSM), a 7-wavelength Aethalometer and a 3-wavelength integrating Nephelometer. A positive matrix factorisation (PMF) was used for the organic aerosol mass spectra analysis to characterise the sources of ambient organic aerosol (OA). Five OA factors were identified: hydrocarbon-like OA (HOA), biomass-burning OA (BBOA), more and less oxygenated OA (LVOOA and SVOOA, respectively), and local hydrocarbon-like OA (LOA). The average absorption (at $470 \mathrm{~nm}$ ) and scattering (at $450 \mathrm{~nm}$ ) coefficients during the entire measurement campaign were $16.59 \mathrm{Mm}^{-1}$ (standard deviation $(\mathrm{SD})=$ 17.23 $\mathrm{Mm}^{-1}$ ) and $29.83 \mathrm{Mm}^{-1}\left(\mathrm{SD}=20.45 \mathrm{Mm}^{-1}\right)$, respectively. Furthermore, the absorption and scattering Angström exponents (AAE and SAE, respectively) and single-scattering albedo (SSA) were calculated. The average AAE value at 470/660 $\mathrm{nm}$ was 0.97 $(\mathrm{SD}=0.16)$ indicating traffic-related black carbon $\left(\mathrm{BC}_{\mathrm{tr}}\right)$ dominance. The average value of SAE (at $\left.450 / 700 \mathrm{~nm}\right)$ was 1.93 $(\mathrm{SD}=0.32)$ and could be determined by the submicron particle $\left(\mathrm{PM}_{1}\right)$ dominance versus the supermicron ones $(\mathrm{PM}>1 \mu \mathrm{m})$. The average value of SSA was $0.62(S D=0.13)$. Several aerosol types showed specific segregation in the SAE versus SSA plot, which underlines different optical properties due to various chemical compositions.
\end{abstract}

\section{Introduction}

Atmospheric aerosols significantly influence both global and local climate, and their loadings have substantially increased since preindustrial times. The impact of particles depends on their chemical composition and physical properties (e.g., optics). The light absorption and light scattering are two main processes of interaction between aerosol particles and solar radiation in the atmosphere. Light-scattering aerosol components (sulphate, sea salt, and others) reduce the warming effect, while light-absorbing aerosol components (black carbon (BC), brown carbon (BrC), mineral dust, and others) contribute to the global warming [1]. In addition, several aerosol components exhibit a wavelength dependence proportional to $\lambda^{-\mathrm{AAE}}$ and $\lambda^{-\mathrm{SAE}}$, where $\lambda$ is the wavelength and AAE and SAE are the absorption and scattering Angström exponents. Hence, the spectral dependence of the aerosol absorption and scattering can be significant to distinguish different components of aerosols [2]. BC can strongly absorb light at all visible wavelengths, and the AAE value varies due to different $\mathrm{BC}$ origins. $\mathrm{SAE}$ is often used as a particle size indicator. Another optical parameter, singlescattering albedo (SSA), has been recently studied in order to evaluate the aerosol radiative forcing [3-5]. Uncertainty in estimating SSA is one of the main reasons of uncertainty in the estimation of the aerosol direct and semidirect effects [4]. The large uncertainty in estimating the aerosol radiative forcing [6] requires better understanding of optical processes in the atmosphere.

Due to various sources, aerosols have different chemical compositions, which affect the particle interaction with solar radiation [7]. Thus, investigation of sources is necessary to assess their climate impacts. Cabada et al. [8] indicated that major components of particulate matter with aerodynamic diameters less than 1 and $2.5 \mu \mathrm{m}\left(\mathrm{PM}_{1}\right.$ and $\mathrm{PM}_{2.5}$, respectively) originate from the same sources, such as combustion (e.g., engine exhausts) and biomass burning. Meanwhile, sources of $\mathrm{PM}_{10}$ (particulate matter with aerodynamic 
diameter less than $10 \mu \mathrm{m}$ ) in the urban environment additionally include road dust and mechanical processes such as brake and tire emissions [9]. Calvo et al. [10] underlined additional natural $\mathrm{PM}_{2.5}$ and $\mathrm{PM}_{10}$ sources: biological particles and wind-suspended natural sources, such as sea spray and surface soil. In agreement with this, Lundgren et al. [11] showed that $\mathrm{PM}_{1}$ is the best indicator of anthropogenic sources since it has higher impact of pollution emissions than of natural sources. Thus, submicron aerosol in the urban environment is of particular interest $[12,13]$. Based on submicron aerosols formation processes, they can be divided into primary and secondary aerosols. Primary aerosols are directly emitted from combustion emissions, while secondary aerosols are formed from gas-phase reactions of emitted precursor gases [14]. Due to various anthropogenic activities, urban areas, particularly megacities, act as hot islands with higher concentrations of aerosols. The urban environment can be used as a natural laboratory to study primary aerosols close to their source. In numerous studies of ambient aerosols, the positive matrix factorisation (PMF) algorithm has been successfully applied for the urban environment [12,15-18]. PMF enables the apportionment of measured organic mass spectra and quantitative evaluation of dominant sources [17].

In our study, several instruments have been used to investigate the optical properties and chemical composition of urban aerosols. In addition, PMF was successfully applied to the organic mass spectra, and the obtained contributions of different sources were quantified. The analysis focuses on assessing the influence of chemical composition on optical parameters (absorption and scattering coefficients, absorption and scattering Angström exponents, and single-scattering albedo). Such an in situ investigation could improve interpretation of observations from remote sensing, provide additional insights into regional and global models of radiative forcing, and improve air quality forecasts at urban sites.

\section{Methods}

2.1. Sampling Site and Instrumentation. Continuous measurements of aerosol mass concentration, size distribution, and optical properties were performed from 11 May to 14 June, 2017. The sampling site is located in Vilnius (Lithuania) $\left(54^{\circ} 38^{\prime} 36^{\prime \prime} \mathrm{N}, 25^{\circ} 10^{\prime} 58^{\prime \prime} \mathrm{E}\right) 12 \mathrm{~m}$ above the ground level. Vilnius is the capital of Lithuania with 0.5 million habitants. The sampling site is $8 \mathrm{~km}$ away from the city centre and can be described as an urban background. In addition, it is located relatively far from the main traffic roads.

$\mathrm{BC}$ concentration and absorption coefficient $\left(B_{\text {abs }}\right)$ were derived from the measurements using a 7-channel Aethalometer (Magee Scientific Company Aethalometers ${ }^{\mathrm{TM}}$, Model AE31 Spectrum, manufactured by Aerosol d.o.o., Slovenia) with 5 min time resolution. The AE31 model operates at 370, $470,520,590,660,880$, and $950 \mathrm{~nm}$ wavelengths. The flow rate through a $2.5 \mathrm{~m}$ long stainless steel tube was $41 / \mathrm{min}$. The Aethalometer measures the real-time light attenuation caused by particles collected on the quartz filter. There are several types of known light-absorbing aerosols in the atmosphere, such as mineral dust, BC, and BrC. Ramachandran et al. [7] showed that $\mathrm{BC}$ contributes $55 \%-70 \%$ of the aerosol radiative forcing at the surface and dominates (57\%-82\%) optical properties and the radiative effects in the urban environment. Chin et al. [19] suggested that, in the urban environment, absorption of solar radiation is mainly attributed to the presence of strong light-absorbing carbonaceous aerosols such as BC. In addition, BC becomes more absorbing as wavelength increases, whereas dust becomes less absorbing [19]. Thus, since BC is the main light absorbent in the ambient air, it is assumed that light attenuation is the result of $\mathrm{BC}$ absorption. The $880 \mathrm{~nm}$ wavelength channel was used for identification of $\mathrm{BC}$ concentration in the ambient air.

The scattering coefficient $\left(B_{\text {scat }}\right)$ was measured using a 3wavelength integrating Nephelometer (TSI model 3563) which measures aerosol light scattering at 450, 550, and $700 \mathrm{~nm}$. Measurements were performed with a flow rate of $20 \mathrm{l} / \mathrm{min}$, $5 \mathrm{~min}$ time resolution, and an automatic calibration every $60 \mathrm{~min}$.

An aerosol chemical speciation monitor (ACSM) (Aerodyne Research, Inc., Billerica, MA, USA) was used for measuring chemical composition of nonrefractory submicron particulate matter $\left(\mathrm{PM}_{1}\right)$. The sampling aerosol flow was $1.6 \mathrm{l} / \mathrm{min}$. In the sampling line, a $\mathrm{PM}_{1}$ impactor inlet was used. During the instrument calibration, determined calibration parameters were set as follows: $\mathrm{RIE}_{\mathrm{NO} 3}=1.1, \mathrm{RIE}_{\mathrm{NH} 4}=9.14$, $\mathrm{RIE}_{\mathrm{SO} 4}=4.2, \mathrm{RIE}_{\text {org }}=1.4$, and $\mathrm{RIE}_{\mathrm{chl}}=1.3$, and the response factor was equal to $2.26 \cdot 10^{-11}$. The resulting particle counting efficiency (CE) was evaluated based on the method suggested by Middlebrook et al. [20] and was equal to 0.5.

A scanning mobility particle sizer (SMPS; TSI model 3080) was used in order to measure the aerosol particle number-size distribution in the range of $6-300 \mathrm{~nm}$. The upscan duration lasted for $4 \mathrm{~min}$ with the repetition of every $5 \mathrm{~min}$. For the SMPS inlet system, an impactor $(0.071 \mathrm{~cm}$ (TSI)) with an effective cut size diameter of $\mathrm{PM}_{1}$ was used. Losses due to the particle diffusion were evaluated using the Gormley-Kennedy equation [21].

Additional measurements including the meteorological parameters (relative humidity, temperature, wind speed, and solar radiation) were measured with $1 \mathrm{~h}$ resolution. All data are given in local time (UTC $+2: 00)$.

2.2. Calculation of Aerosol Optical Properties. $B_{\mathrm{abs}}$ and BC concentration can be calculated based on light attenuation measurements on a quartz filter. Previous studies [22, 23] investigated the main factors leading to the inaccuracy of measurements: the multiple scattering effect of filter fibres and increased particle loading on the filter, known as the shadow effect. Thus, the Weingartner correction [24] was applied, and additional calibration factors $(C$ and $R$ ) were used:

$$
B_{\mathrm{abs}}=B_{\mathrm{ATN}} \frac{1}{C \cdot R(\mathrm{ATN})},
$$

where $B_{\mathrm{ATN}}$ is delivered from attenuation measurements but does not include any corrections. For factor $C$, the constant value of 3.3 was used, and the value of factor $R$ was calculated by the following equation [24]: 


$$
R(\mathrm{ATN})=\left(\frac{1}{f}-1\right) \frac{\ln (\mathrm{ATN})-\ln (10 \%)}{\ln (50 \%)-\ln (10 \%)}+1,
$$

where parameter $f=1.09$ was chosen based on the study by Sandradewi et al. [25].

Based on the wavelength-dependent $B_{\text {abs }}$ and $B_{\text {scat }}$, absorption and scattering Angström exponents were estimated as follows [26]:

$$
\begin{aligned}
& \operatorname{AAE}_{470 / 660}=-\frac{\ln \left(B_{\mathrm{abs}_{470}} / B_{\mathrm{abs}_{660}}\right)}{\ln (470 / 660)}, \\
& \operatorname{SAE}_{450 / 700}=-\frac{\ln \left(B_{\mathrm{scat}_{450}} / B_{\mathrm{scat}_{700}}\right)}{\ln (450 / 700)} .
\end{aligned}
$$

Based on $B_{\text {abs }}$ and $B_{\text {scat }}$, SSA was calculated by the following equation [27]:

$$
\mathrm{SSA}_{550}=\frac{B_{\mathrm{scat}_{550}}}{B_{\mathrm{scat}_{500}}+B_{\mathrm{abs}_{520}}} .
$$

Due to the wavelength difference between $B_{\mathrm{scat}}$ and $B_{\mathrm{abs}}$, the additional uncertainty of $5 \%$ was evaluated by the relation suggested by Zhuang et al. [26] and should be applied to SSA values.

For further BC analysis, additional calculations were performed. Since several studies $[25,28-30]$ identified specific AAE values for traffic $(1 \pm 0.1)$ and wood burning (between 1.9 and 2.2), $\mathrm{BC}$ mass concentration was recalculated to $\mathrm{BC}$ concentration related to traffic $\left(\mathrm{BC}_{\mathrm{tr}}\right)$ and wood burning $\left(\mathrm{BC}_{\mathrm{wb}}\right)$ according to the "Aethalometer model" [25]:

$$
\begin{aligned}
\frac{B_{\mathrm{abs}_{\mathrm{tr}, 400}}}{B_{\mathrm{abs}_{\mathrm{tr}, 880}}}=\left(\frac{470}{880}\right)^{-\mathrm{AAE}_{\mathrm{tr}},} \\
\frac{B_{\mathrm{abs}_{\mathrm{wb}, 470}}}{B_{\mathrm{abs}_{\mathrm{wb}, 880}}}=\left(\frac{470}{880}\right)^{-\mathrm{AAE}_{\mathrm{wb}},} \\
B_{\mathrm{abs}_{\lambda}}=B_{\mathrm{abs}_{\mathrm{tr}, \lambda}}+B_{\mathrm{abs}_{\mathrm{wb}, \lambda} .} .
\end{aligned}
$$

$B C$ source apportionment was performed with chosen values $\left(\mathrm{AAE}_{\mathrm{tr}}=1\right.$ and $\left.\mathrm{AAE}_{\mathrm{wb}}=2\right)$ and calculated as follows [31]:

$$
\begin{aligned}
\mathrm{BC}_{\mathrm{tr}} & =\mathrm{BC} \cdot \frac{B_{\mathrm{abs}_{\mathrm{tr}, 880}}}{B_{\mathrm{abb}_{880}}} \\
\mathrm{BC}_{\mathrm{wb}} & =\mathrm{BC} \cdot \frac{B_{\mathrm{abs}_{\mathrm{wb}, 880}}}{B_{\mathrm{abs}_{880}}} .
\end{aligned}
$$

The concentrations of both, $\mathrm{BC}_{\mathrm{tr}}$ and $\mathrm{BC}_{\mathrm{wb}}$, and their contribution to the total $\mathrm{BC}$ have been evaluated and are reported in this study.

2.3. Positive Matrix Factorisation. Positive matrix factorisation (PMF) is the statistical tool, which represents the time series of measured organic mass spectra as several subgroups characterised by factor profiles [14]. In order to run PMF, SoFi Standard and SoFi Pro software was used. The PMF procedure was performed as specified by Crippa et al. [32], and several external time series $\left(\mathrm{BC}_{\mathrm{tr}}\right.$ and $\left.\mathrm{BC}_{\mathrm{wb}}\right)$ were added. Selecting the best modelled number of factors for a data set was performed by finding the ratio of the total sum of the squares of the scaled residuals and their expected value $\left(Q / Q_{\exp }\right)$ to be close to 1 . Values of $Q / Q_{\exp }$ " 1 show the underestimation of the errors of variability in the factor profiles, and $Q / Q_{\exp }$ " 1 indicates the overestimation of the input data errors [33]. After investigation of the number of factors, several factor profiles were constrained by external profiles with $a$ value. The technique of $a$ value allows constrained factor profiles to vary within the error bar of the scalar value $a$ [14]. The following step included the dynamic criteria-based selection, which enables comparison with external data. The last part of selecting the solution was performed by testing the stability between runs. For this aim, the bootstrap resampling mechanism was used by performing 1000 runs. The bootstrap analysis randomly decomposes the original data set by resampling [34] and allows to certify if solution is statistically reliable.

\section{Results and Discussion}

3.1. Campaign Overview. During the entire measurement campaign, the nonrefractory $\mathrm{PM}_{1}$ consisted of organics (84\%, $\left.6.35 \mu \mathrm{g} \cdot \mathrm{m}^{-3} \quad\left(\mathrm{SD}=4.00 \mu \mathrm{g} \cdot \mathrm{m}^{-3}\right)\right)$, nitrate $\left(9 \%, 0.66 \mu \mathrm{g} \cdot \mathrm{m}^{-3}\right.$ $\left.\left(\mathrm{SD}=0.51 \mu \mathrm{g} \cdot \mathrm{m}^{-3}\right)\right)$, ammonium $\quad\left(4 \%, 0.32 \mu \mathrm{g} \cdot \mathrm{m}^{-3} \quad(\mathrm{SD}=\right.$ $\left.\left.0.20 \mu \mathrm{g} \cdot \mathrm{m}^{-3}\right)\right)$, and sulphate $\left(3 \%, \quad 0.20 \mu \mathrm{g} \cdot \mathrm{m}^{-3} \quad(\mathrm{SD}=\right.$ $\left.0.12 \mu \mathrm{g} \cdot \mathrm{m}^{-3}\right)$ ) (Figure $1(\mathrm{a})$ ). The average temperature was $13.18^{\circ} \mathrm{C}\left(\mathrm{SD}=4.68^{\circ} \mathrm{C}\right)$, average wind speed was $0.13 \mathrm{~m} \cdot \mathrm{s}^{-1}$ $\left(\mathrm{SD}=0.19 \mathrm{~m} \cdot \mathrm{s}^{-1}\right)$, and average relative humidity was $59.22 \%$ $(\mathrm{SD}=19.96 \%)$.

3.2. Source Apportionment. PMF, which is the most commonly used source apportionment method for ACSM data, was applied in our study to investigate sources of organics. PMF solutions with any higher number of factors than five were not stable for different runs. Thus, five types of organic aerosol (OA) were identified in the Vilnius urban background site: hydrocarbon-like organic aerosol (HOA), biomass-burning organic aerosol (BBOA), more and less oxygenated organic aerosols (LVOOA and SVOOA, respectively), and local hydrocarbon-like organic aerosol (LOA) (Figures 1(b)-1(h)). HOA, BBOA, and LOA factors were constrained with external factor profiles [32] with $a$ values equal to $0.2,0.4$, and 0.2 , respectively. There were three dynamic criteria: $\mathrm{HOA}$ correlation with $\mathrm{BC}_{\mathrm{tr}}$, $\mathrm{BBOA}$ correlation with $\mathrm{BC}_{\mathrm{wb}}$, and contribution of the fraction of the total organic mass measured at $m / z 60$ (abbreviated as $f_{60}$ ) to BBOA.

Dominant peaks of factor profiles, known as key tracers, were used in order to identify each OA source. Key tracers of HOA in ACSM mass spectra are the enhanced signals at $\mathrm{m} / \mathrm{z}$ $41\left(\mathrm{C}_{3} \mathrm{H}_{5}^{+}\right)$and $43\left(\mathrm{C}_{3} \mathrm{H}_{7}^{+}\right)$and the typical alkene-like structure ions $\mathrm{C}_{4} \mathrm{H}_{7}^{+}$and $\mathrm{C}_{4} \mathrm{H}_{9}^{+}(\mathrm{m} / z 55$ and 57, respectively) [35]. BBOA was identified by two enhanced signals at $m / z 60$ and 73 , which are associated with levoglucosan and indicate ions $\mathrm{C}_{2} \mathrm{H}_{4} \mathrm{O}_{2}^{+}$and $\mathrm{C}_{3} \mathrm{H}_{5} \mathrm{O}_{2}^{+}$, respectively [36]. Levoglucosan is 
(a)
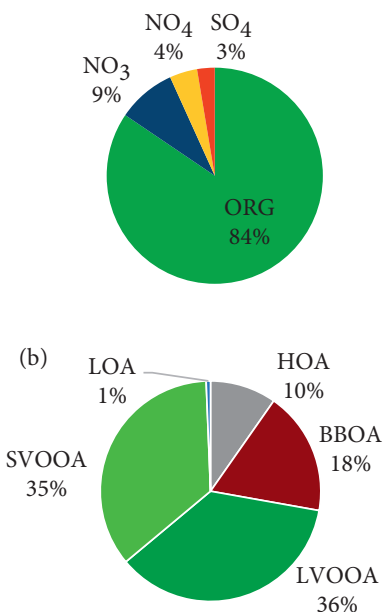

(c)

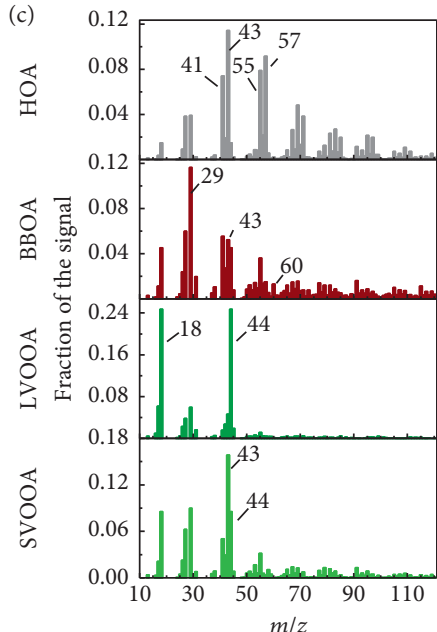

(f)

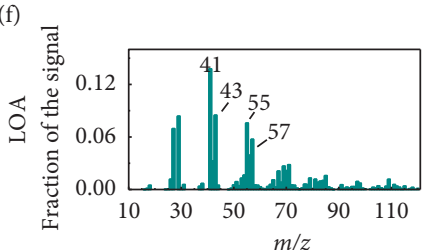

(d)

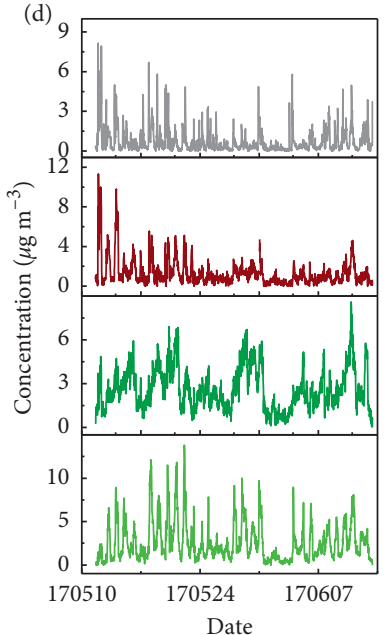

(g)

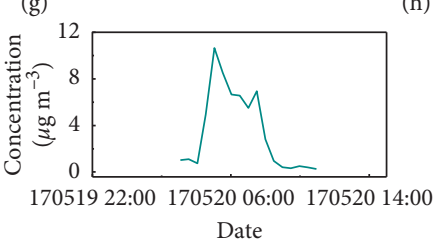

(e)

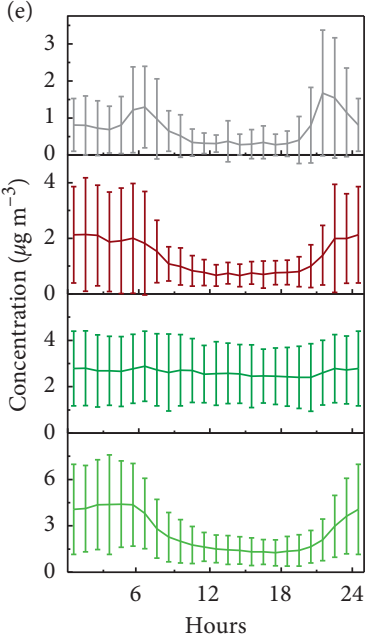

(h)

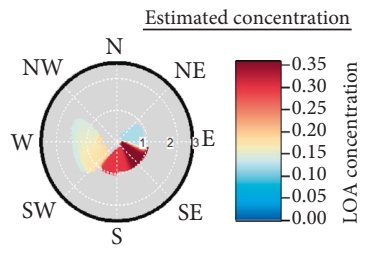

Figure 1: (a) Contributions of organics (green), sulphate (red), nitrate (blue), and ammonium (yellow) during the measurement campaign. (b) PMF solutions contributions to organics: SVOOA (light green), LVOOA (dark green), BBOA (brown), and HOA (grey) factors: (c) their mass spectra; (d) time series; (e) diurnal time trends. LOA: (f) mass spectra; (g) time series; (h) wind rose (blue).

derived from pyrolysis of various cellulose at high temperatures, and it is a main molecular tracer of biomass-burning aerosols [37]. An additional key tracer of BBOA was $m / z 29$ $\left(\mathrm{CHO}^{+}\right)$[38]. Moreover, the higher intensity of $m / z 43$ than $\mathrm{m} / z 44$ showed the dominance of fresh and local BBOA versus long-range transport-related $\mathrm{BBOA}$. The oxygenated $\mathrm{OA}$ was effectively divided into two factors: LVOOA and SVOOA. LVOOA showed several typical peaks of $m / z 18\left(\mathrm{H}_{2} \mathrm{O}^{+}\right), 28$ $\left(\mathrm{CO}^{+}\right)$, and $44\left(\mathrm{CO}_{2}^{+}\right)$[39], which together with low intensity of $\mathrm{m} / z 43$ versus $\mathrm{m} / \mathrm{z} 44$ indicate highly oxidised species, known as aged OA. SVOOA is characterised by the highest peak at $m / z 43\left(\mathrm{C}_{2} \mathrm{H}_{3} \mathrm{O}^{+}\right)$and indicates freshly oxidised $\mathrm{OA}$ species [39]. The last identified factor LOA was of hydrocarbon-like organic origin with key tracers of $m / z 41$, 55 , and 57. Due to different origin and specific intensities of tracer-linked signals, LOA was successfully extracted from OA mass spectra.

At the beginning of the measuring campaign, domestic heating was a reason for higher $\mathrm{BBOA}$ concentration, and its contribution to OA during the entire measuring campaign was $18 \%$ with the average value of $1.31 \mu \mathrm{g} \cdot \mathrm{m}^{-3}(\mathrm{SD}=$ $1.34 \mu \mathrm{g} \cdot \mathrm{m}^{-3}$ ). As expected, the main contributors to OA were LVOOA and SVOOA, whose inputs reached $34 \%$ and $38 \%$, respectively. The average concentration of LVOOA was $2.64 \mu \mathrm{g} \cdot \mathrm{m}^{-3}\left(\mathrm{SD}=1.42 \mu \mathrm{g} \cdot \mathrm{m}^{-3}\right)$, while that of SVOOA was $2.56 \mu \mathrm{g} \cdot \mathrm{m}^{-3}\left(\mathrm{SD}=2.20 \mu \mathrm{g} \cdot \mathrm{m}^{-3}\right)$. LVOOA showed a moderate correlation with sulphate $(r=0.49)$ and had no diurnal trend which suggests a strong influence of long-range transport. SVOOA was correlated with nitrate $(r=0.50)$. A diurnal trend of SVOOA concentration showed an increment during the night (from 2 to $5 \mathrm{am}$ ) and reached the maximum value of
$4.42 \mu \mathrm{g} \cdot \mathrm{m}^{-3}$. A diurnal trend of HOA concentration showed two diurnal peaks. The first peak appeared during morning rush hours $(6-8 \mathrm{~h})$, while the second is associated with the decrement of the atmosphere mixing height in the late evening hours (10-11 pm). Also, HOA showed a great agreement with external data: the correlation coefficient between $\mathrm{HOA}$ and $\mathrm{BC}_{\mathrm{tr}}$ was 0.65 . The LOA factor appeared only once during an event (20 May 2017) and lasted for $6 \mathrm{~h}$ (from $3 \mathrm{am}$ to $8 \mathrm{am}$ ). The concentration of LOA reached the maximum value of $10.7 \mu \mathrm{g} \cdot \mathrm{m}^{-3}$. The additional meteorological analysis showed that LOA particles were transported from the southern part of the city. No fire incidents or other emissions were reported at the time of event; therefore, the source of LOA could not be identified.

For the entire investigation campaign, two main BCcontributing sources (traffic and wood burning) were identified, and their contribution to $\mathrm{BC}$ concentration was evaluated (Figure 2). The average $\mathrm{BC}$ concentration was $1.26 \mu \mathrm{g} \cdot \mathrm{m}^{-3}\left(\mathrm{SD}=1.35 \mu \mathrm{g} \cdot \mathrm{m}^{-3}\right)$. These results are consistent with those obtained during the previous studies in Vilnius during the warm period [40] and appear in the typical OA concentration range $\left(1-10 \mu \mathrm{g} \cdot \mathrm{m}^{-3}\right)$ for urban environments [41]. The biggest contributor to the total $\mathrm{BC}$ was $\mathrm{BC}_{\text {tr }}$ whose input reached $92 \%$. The average $\mathrm{BC}_{\mathrm{tr}}$ concentration was $1.23 \mu \mathrm{g} \cdot \mathrm{m}^{-3}\left(\mathrm{SD}=1.29 \mu \mathrm{g} \cdot \mathrm{m}^{-3}\right) . \mathrm{BC}_{\mathrm{tr}}$ concentration showed a diurnal trend with two peaks corresponding to the $\mathrm{HOA}$ diurnal trend. The $\mathrm{BC}_{\mathrm{wb}}$ contribution to the $\mathrm{BC}$ was only $8 \%$, and the average concentration was $0.13 \mu \mathrm{g} \cdot \mathrm{m}^{-3}$ ( $\mathrm{SD}=$ $\left.0.18 \mu \mathrm{g} \cdot \mathrm{m}^{-3}\right) . \mathrm{BC}_{\mathrm{wb}}$ concentration showed no peaks in the diurnal trend. These results suggest that, during the warm season, no significant local wood-burning sources were 


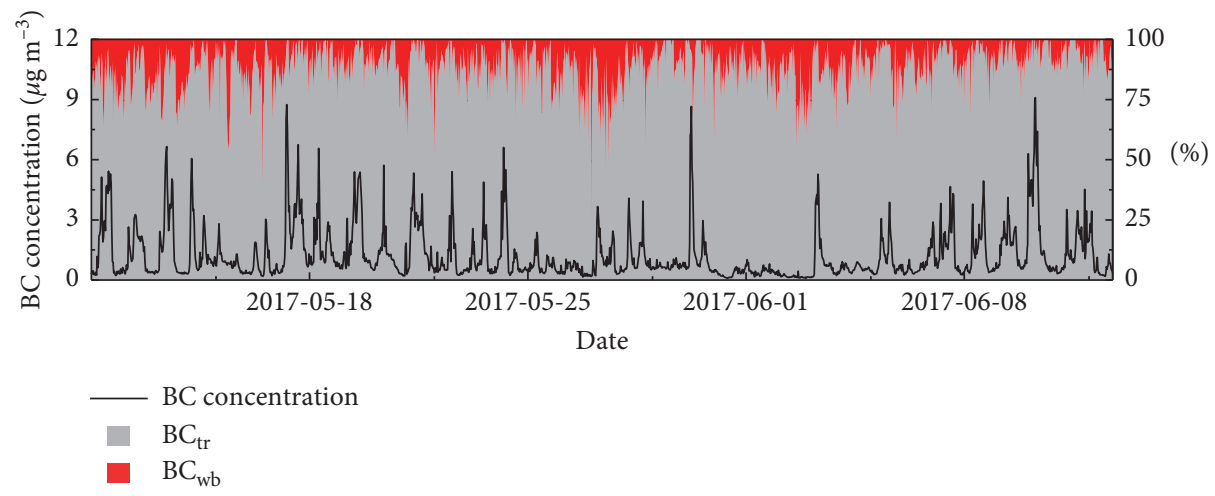

Figure 2: Time series of $\mathrm{BC}$ concentration (black) and contributions of $\mathrm{BC}_{\mathrm{tr}}$ (grey) and $\mathrm{BC}_{\mathrm{wb}}$ (brown) to the $\mathrm{BC}$ concentration.

identified and the main $\mathrm{BC}$ source was the traffic-related exhaust.

\subsection{Temporal Variations in the Aerosol Optical Properties.} Several optical properties were calculated, and their variations in time were observed during the entire investigation campaign. The calculated $B_{\text {abs }}$ average value was $16.59 \mathrm{Mm}^{-1}$ $\left(\mathrm{SD}=17.23 \mathrm{Mm}^{-1}\right)$, and its temporal variation strongly correlated with that of $\mathrm{BC}_{\mathrm{tr}}(r=0.98)$ and moderately correlated with that of HOA $(r=0.68)$ (Figure 3(b)), which suggests that the absorption coefficient is mainly determined by traffic-related exhaust. The evaluated $B_{\text {abs }}$ values in this study were 2.8 times higher than the $B_{\mathrm{abs}}$ values reported in the study performed in a small-sized urban environment in Spain for the warm season [42]. The results obtained in our study were close to those obtained at an urban site in Granada (Spain) [43]. Meantime, in comparison to $B_{\mathrm{abs}}$ determined in cities like Beijing, Nanjing, and Wuhan, the $B_{\text {abs }}$ values obtained in this study were from 1.8 to 7.2 times lower compared to those reported in [44].

The $B_{\text {scat }}$ coefficient was directly obtained from Nephelometer measurements, and its links to several other parameters were investigated. $B_{\text {scat }}$ varied from 5.23 to $118.15 \mathrm{Mm}^{-1}$ with the average value of $29.83 \mathrm{Mm}^{-1}$ ( $\mathrm{SD}=$ $\left.20.45 \mathrm{Mm}^{-1}\right)$. $B_{\text {scat }}$ temporal variation showed strong correlation with $\mathrm{BBOA}(r=0.80)$ and the aerosol particle number concentration from 100 to $300 \mathrm{~nm}$ in size $\left(N_{100-300}\right)$ $(r=0.75)$ (Figure 3(a)). These results are in agreement with those reported by Wang et al. [45], which suggests that mainly particles from 200 to $800 \mathrm{~nm}$ in size contributed to the light-scattering coefficient.

AAE is a well-known light absorption-related parameter, which is widely used for BC source assessment. Several studies reported AAE values for traffic (from 0.9 to 1.1) and wood burning (from 1.9 to 2.2 ) $[25,30,31,46]$ and brown carbon $(\mathrm{BrC})(\mathrm{AAE}=2.5)$ [47]. In addition, it was observed that AAE showed high variability due to the coating thickness [48]. In our study, an average value of AAE was 0.97 with a low standard deviation $(\mathrm{SD}=0.16)$. This agrees with an assumption that the absorption parameters were driven by traffic-related exhaust. The lowest values of the AAE diurnal trend appeared in the morning (5-7 am) and late evening $(8-10 \mathrm{pm})$ together with the highest values of the BCtr diurnal trend.
SAE is often regarded as an indicator of dominant size of particles: $\mathrm{SAE}_{467,660}>2$ indicates an optical dominance of fine particles [49]. Cappa et al. [27] suggested that $\mathrm{SAE}_{450,550}=1.3$ is a dividing value between submicron aerosol $\left(\mathrm{PM}_{1}\right)$ and supermicron aerosol $(\mathrm{PM}>1 \mu \mathrm{m})$. In our study, the average value of SAE was $1.93(\mathrm{SD}=0.32)$, which indicates the optical dominance of submicron particles. In the diurnal trend of SAE, the highest value was reached at 3 am $(\mathrm{SAE}=2.1)$ which could be related to the SVOOA formation during the nighttime.

SSA is a parameter, which depends on both particle size and its origin. SSA is defined as the ratio of the scattering coefficient and the extinction coefficient, which is the sum of the scattering and absorption coefficients. The value of SSA can be used to evaluate the aerosol radiative forcing [50] and to investigate the relationship between aerosol scattering and absorption [51]. The SSA value decreases with the increasing size of aerosol particles [52]. Goto et al. [53] demonstrated a relation between SSA and BC concentration and the regression slope in the SSA versus BC plot varied from negative to positive depending on particle size. Bond and Bergstrom [54] showed that fresh BC particles correspond to a low SSA value. Pokhrel et al. [4] reported that SSA could not be directly parameterised based on the fuel type due to the influence of burning conditions. Thus, SSA is a complex parameter, and more detailed investigation is needed. In our study, SSA varied between 0.19 and 0.90 with the average value of $0.62(\mathrm{SD}=0.13)$. These results are slightly lower than those reported in the urban study in Granada (Spain) [43]. SSA showed a moderate negative correlation with BC $(r=-0.67)$, and the diurnal trend had two lowest values during morning rush hours $(6-7 \mathrm{am})$ and late evening hours (9-10 pm) associated with the decrement of the atmosphere mixing height.

3.4. SAE versus SSA Plot Analysis. In order to investigate the influence of particles' origin on their optical properties, SAE versus SSA graphs were depicted for several different sources of aerosol particles (Figure 4). SAE and SSA were chosen due to sensitivity to the particle size and complexity, respectively. In the SAE versus SSA plot, concentrations of HOA, BBOA, LOA, SVOOA, LVOOA, secondary inorganic aerosol (SIA), $\mathrm{BC}_{\mathrm{tr}}$, and $\mathrm{BC}_{\mathrm{wb}}$ were plotted as the size of data points. As can 


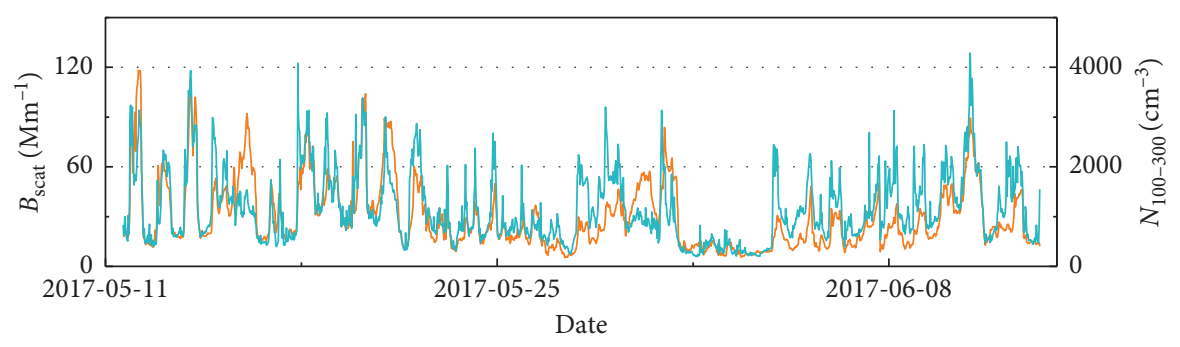

$\begin{array}{ll}- & N_{100-300} \\ - & B_{\text {scat }}\end{array}$

(a)

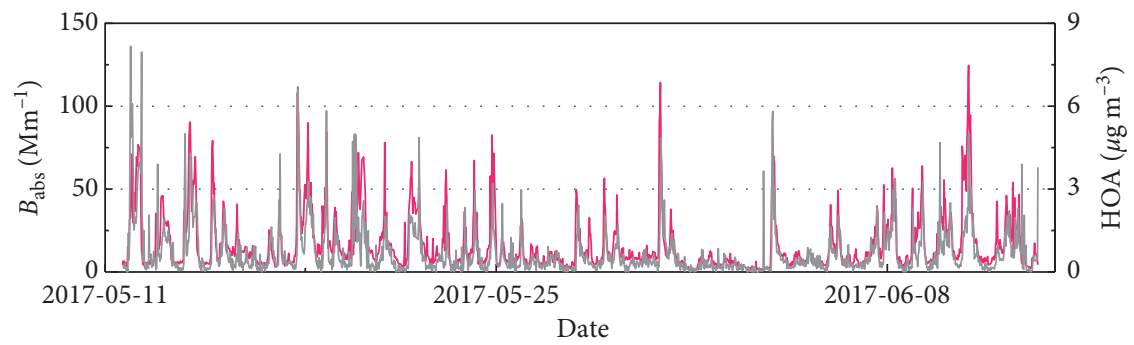

HOA
- Babs

(b)

Figure 3: Temporal variations in (a) $B_{\text {scat }}$ (yellow) and $N_{100-300}$ (blue) and (b) $B_{\text {abs }}$ (pink) and HOA (grey).

be seen in Figure 4(a), the highest concentration of HOA appeared within a wide range of SSA (from 0.2 to 0.6 ) and SAE lower than 2.1, which indicates that bigger particles absorb light slightly better. In the SAE versus SSA plot of $\mathrm{BC}_{\mathrm{tr}}$, the range of SSA and SAE for the highest $\mathrm{BC}_{\mathrm{tr}}$ concentration appears on the left side of the graph (SSA <0.4). Due to the light absorption by $\mathrm{BC}_{\mathrm{tr}}$, light extinction increases and the value of SSA decreases. Furthermore, particle size does not influence absorption. A slight difference between $\mathrm{HOA}$ and $\mathrm{BC}_{\mathrm{tr}}$ could appear due to different chemical compositions: $\mathrm{BC}_{\mathrm{tr}}$ contains inorganic materials, which strongly absorb light, while HOA is one of the OA factors and contains a light-scattering material. For both, BBOA and $\mathrm{BC}_{\mathrm{wb}}$, the highest concentrations appear in the range of SSA $>0.35$. In addition, SSA increases with SAE increment, which suggests that aerosol radiative forcing of BBOA and $\mathrm{BC}_{\mathrm{wb}}$ strongly depends on the particle size. In the SAE versus SSA plot, the concentrations of SVOOA, LVOOA, and SIA were less distributed. The highest concentration of SVOOA appeared in the central part of the plot, which corresponds to the SAE values between 1.2 and 1.8 and the SSA values between 0.4 and 0.6. A higher concentration of LVOOA appeared in the upper part of the SAE versus SSA plot with no significant changes in the SSA axis. For a higher concentration of LVOOA, SAE varied between 2.0 and 2.7. In the SAE versus SSA plot for a higher SIA concentration, one particular region was not observed. For all, SVOOA, LVOOA, and SIA, the left part of the plot $(\mathrm{SAE}<0.35)$ shows the lowest concentrations which indicates dominance of scattering versus absorption. The LOA concentration in the plot of SAE versus SSA was also depicted. The highest concentration of LOA appeared in a small range of both SAE (from 1.82 to 1.89 ) and SSA (from 0.50 to 0.62 ). LOA is another hydrocarbon-like organic aerosol, but it has a different (not defined) source than HOA. The SSA values of the highest concentrations of HOA and LOA were different, which could indicate SSA diversity due to different sources of burning fuel, but this could not be used as a direct indicator.

\section{Conclusions}

The ground-based measurements of light aerosol absorption and scattering and chemical composition were performed in the urban environment during May-June, 2017. The applied PMF analysis showed five main OA sources (HOA, BBOA, SVOOA, LVOOA, and LOA). The BBOA concentration showed a decrement with increased ambient temperatures due to the end of domestic heating usage, while the contributions of other factors (HOA, SVOOA, and LVOOA) were significant during the entire measurement campaign. The local LOA factor appeared during one event and was formed in the southern part of the city due to an unknown source. The analysis of light absorption parameters showed that the absorption coefficient and $\mathrm{AAE}$ were determined by the traffic exhaustrelated $\mathrm{BC}_{\mathrm{tr}}$. Light-scattering parameters ( $\mathrm{SAE}$ and $B_{\text {scat }}$ ) analysis suggested that the light scattering in the ambient air was mainly caused by submicron particles $\left(\mathrm{PM}_{1}\right)$. The calculated SSA values varied between 0.19 and 0.90 , indicating the influence of various components and different particle sizes. In the SAE versus SSA plot, traffic 


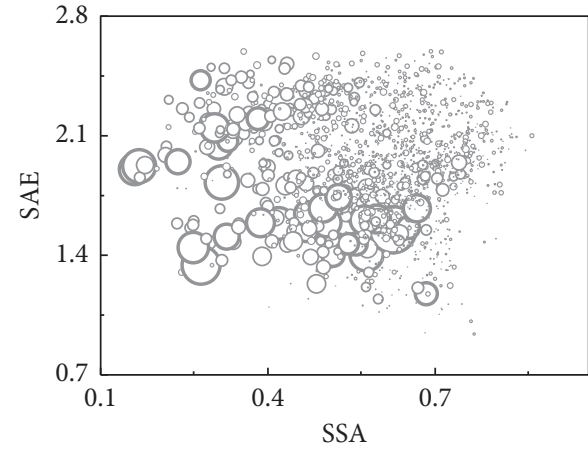

(a)

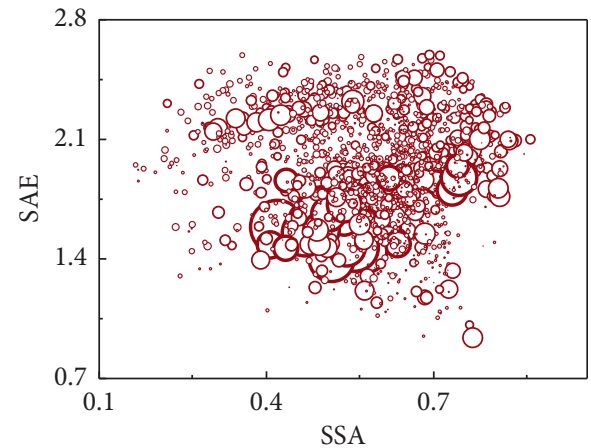

(c)

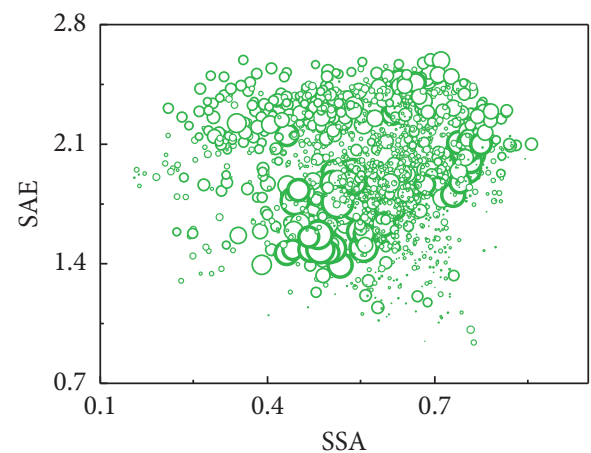

(e)

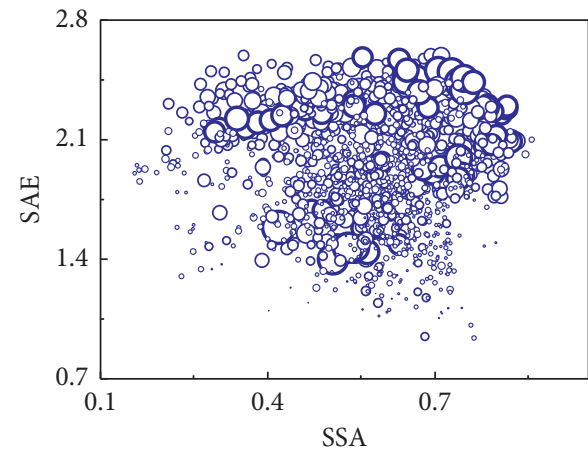

(g)

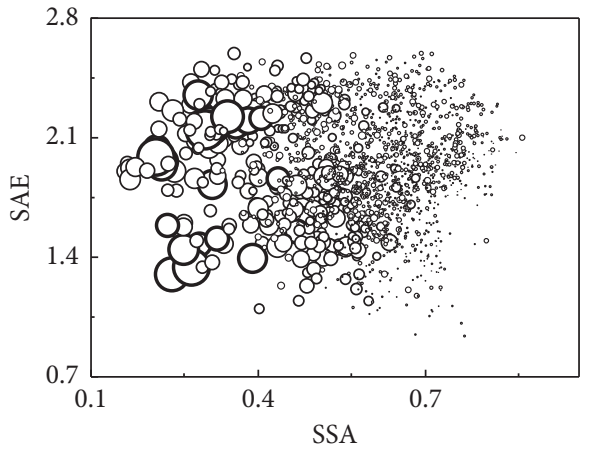

(b)

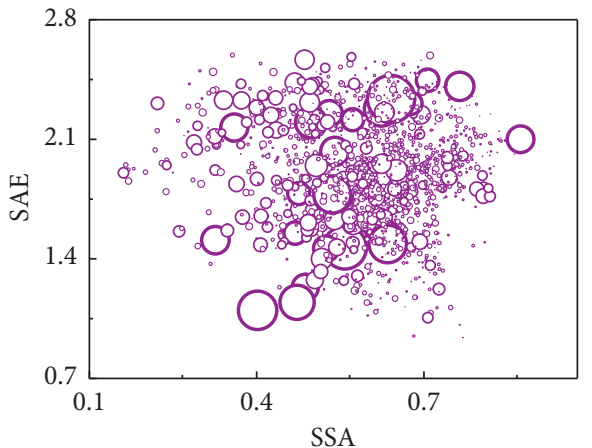

(d)

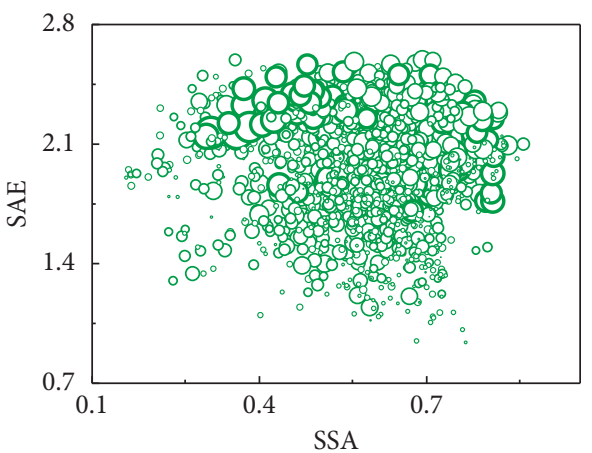

(f)

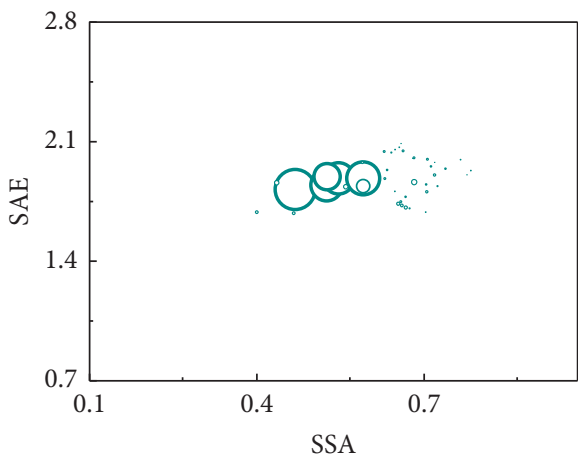

(h)

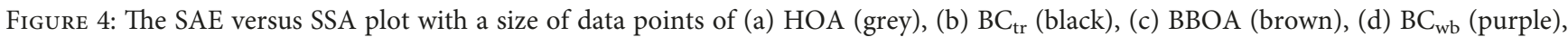
(e) SVOOA (light green), (f) LVOOA (dark green), (g) SIA (dark blue), and (h) LOA (light blue) for the entire measurement campaign.

exhaust-related $\mathrm{BC}_{\text {tr }}$ particles appeared within the range of small SSA values $(S S A<0.4)$. Another traffic exhaustrelated aerosol HOA due to different chemical compositions showed a wider SSA range $(0.2<$ SSA $<0.6)$. For biomass- and wood-burning aerosols (BBOA and $\mathrm{BC}_{\mathrm{wb}}$ ), SSA values increased with the increment of SAE, 
indicating the importance of particle size for their optical properties. SVOOA, LVOOA, and SIA showed the smallest concentration for small SSA values (SSA $<0.35$ ), indicating their strong dominance of scattering versus absorption in a wide range of particle size. The highest concentrations of LOA appeared within the SSA values between 0.50 and 0.62 , and they were different from the dominant SSA values for the highest HOA concentration. Therefore, SSA varies due to different origin of hydrocarbon-like aerosols, but this could not be used as a direct indicator of the type of fuel. Thus, due to the different dominant sources of aerosols, the optical properties $\left(B_{\mathrm{abs}}, \mathrm{AAE}\right.$, and SSA) can change and, as a result, influence the radiative forcing. The results of this study can provide additional insights into forecasting the radiative forcing both on the local and global scales.

\section{Nomenclature}

AAE: Absorption Angström exponent

$\mathrm{AAE}_{\text {tr: }}$ Absorption Angström exponent values for traffic

$\mathrm{AAE}_{\mathrm{wb}}$ : Absorption Angström exponent values for wood burning

ACSM: Aerosol chemical speciation monitor

ATN: Filter attenuation

$B_{\text {abs }}$ : Absorption coefficient

$B_{\text {ATN }}$ Attenuation coefficient

BBOA: Biomass-burning organic aerosol

BC: $\quad$ Black carbon

$\mathrm{BC}_{\mathrm{tr}}$ : Traffic-related black carbon

$\mathrm{BC}_{\mathrm{wb}}$ : Wood-burning-related black carbon

BrC: $\quad$ Brown carbon

$B_{\text {scat }}$ : Scattering coefficient

$C: \quad$ Calibration factor

CE: $\quad$ Counting efficiency

$f: \quad$ Parameter estimating the slope of the $B_{\text {ATN }}$ versus ATN curve

HOA: Hydrocarbon-like organic aerosol

LOA: Local hydrocarbon-like organic aerosol

LVOOA: Low-volatile oxygenated organic aerosol

OA: Organic aerosol

$\mathrm{PM}_{1}$ : $\quad$ Particulate matter with aerodynamic diameter less than $1 \mu \mathrm{m}$

$\mathrm{PM}_{10}$ : Particulate matter with aerodynamic diameter less than $10 \mu \mathrm{m}$

$\mathrm{PM}_{2.5}$ : $\quad$ Particulate matter with aerodynamic diameter less than $2.5 \mu \mathrm{m}$

PMF: $\quad$ Positive matrix factorisation

Q: $\quad$ Total sum of the squares of the scaled residuals in the PMF matrix

$Q_{\text {exp }}$ : $\quad$ Expected value of $Q$

$R: \quad$ Calibration factor

$r: \quad$ Correlation coefficient

SAE: $\quad$ Scattering Angström exponent

SD: $\quad$ Standard deviation

SSA: $\quad$ Single-scattering albedo

SVOOA: Semivolatile oxygenated organic aerosol

$\lambda$ : Wavelength.

\section{Data Availability}

The aerosol chemical composition and optical parameters data used to support the findings of this study are available from the corresponding author upon request.

\section{Conflicts of Interest}

The authors declare that they have no conflicts of interest.

\section{Acknowledgments}

The research leading to these results was funded by the National Research Programme, "Sustainability of agro-, forest and water ecosystems" (project FOREstRESS, No. SIT3/2015). Part of this work was supported by the COST Action CA16109 COLOSSAL (Chemical On-Line cOmpoSition and Source Apportionment of fine aerosoL).

\section{References}

[1] M. Z. Jacobson, "Strong radiative heating due to the mixing state of black carbon in atmospheric aerosols," Nature, vol. 409, no. 6821, pp. 695-697, 2001.

[2] M. Collaud Coen, E. Weingartner, D. Schaub et al., "Saharan dust events at the Jungfraujoch: detection by wavelength dependence of the single scattering albedo and analysis of the events during the years 2001 and 2002," Atmospheric Chemistry and Physics Discussions, vol. 3, no. 6, pp. 55475594, 2003.

[3] C. Lacagnina, O. P. Hasekamp, H. Bian et al., "Aerosol singlescattering albedo over the global oceans: comparing PARASOL retrievals with AERONET, OMI, and AeroCom models estimates," Journal of Geophysical Research: Atmospheres, vol. 120, no. 18, pp. 9814-9836, 2015.

[4] R. P. Pokhrel, N. L. Wagner, J. M. Langridge et al., "Parameterization of single-scattering albedo (SSA) and absorption Ångström exponent (AAE) with EC/OC for aerosol emissions from biomass burning," Atmospheric Chemistry and Physics, vol. 16, no. 15, pp. 9549-9561, 2016.

[5] K. Lewis, W. P. Arnott, H. Moosmüller, and C. E. Wold, "Strong spectral variation of biomass smoke light absorption and single scattering albedo observed with a novel dualwavelength photoacoustic instrument," Journal of Geophysical Research, vol. 113, no. D16, pp. 1-14, 2008.

[6] P. Forster, V. Ramaswamy, P. Artaxo et al., "Changes in atmospheric constituents and in radiative forcing," Physical Review B, vol. 77, no. 22, pp. 129-234, 2008.

[7] S. Ramachandran, R. Srivastava, S. Kedia, and T. A. Rajesh, "Contribution of natural and anthropogenic aerosols to optical properties and radiative effects over an urban location," Environmental Research Letters, vol. 7, no. 3, article 034028, 2012.

[8] J. C. Cabada, S. Rees, S. Takahama et al., "Mass size distributions and size resolved chemical composition of fine particulate matter at the Pittsburgh supersite," Atmospheric Environment, vol. 38, no. 20, pp. 3127-3141, 2004.

[9] T. B. Councell, K. U. Duckenfield, E. R. Landa, and E. Callender, "Tire-wear particles as a source of zinc to the environment," Environmental Science \& Technology, vol. 38, no. 15, pp. 4206-4214, 2004.

[10] A. I. Calvo, C. Alves, A. Castro, V. Pont, A. M. Vicente, and R. Fraile, "Research on aerosol sources and chemical 
composition: past, current and emerging issues," Atmospheric Research, vol. 120-121, pp. 1-28, 2013.

[11] D. A. Lundgren, D. N. Hlaing, T. A. Rich, and V. A. Marple, " $\mathrm{PM}_{10} / \mathrm{PM}_{2.5} / \mathrm{PM}_{1}$ data from a trichotomous sampler," Aerosol Science and Technology, vol. 25, no. 3, pp. 353-357, 1996.

[12] J. E. Petit, O. Favez, J. Sciare et al., "Submicron aerosol source apportionment of wintertime pollution in Paris, France by double positive matrix factorization $\left(\mathrm{PMF}_{2}\right)$ using an aerosol chemical speciation monitor (ACSM) and a multi-wavelength Aethalometer," Atmospheric Chemistry and Physics, vol. 14, no. 24, pp. 13773-13787, 2014.

[13] S. H. Budisulistiorini, K. Baumann, E. S. Edgerton et al., "Seasonal characterization of submicron aerosol chemical composition and organic aerosol sources in the southeastern United States: Atlanta, Georgia, and Look Rock, Tennessee," Atmospheric Chemistry and Physics, vol. 16, no. 8, pp. 51715189, 2016.

[14] F. Canonaco, M. Crippa, J. G. Slowik, U. Baltensperger, and A. S. H. Prévôt, "SoFi, an IGOR-based interface for the efficient use of the generalized multilinear engine (ME-2) for the source apportionment: ME-2 application to aerosol mass spectrometer data," Atmospheric Measurement Techniques, vol. 6, no. 12, pp. 3649-3661, 2013.

[15] N. L. Ng, S. C. Herndon, A. Trimborn et al., “An aerosol chemical speciation monitor (ACSM) for routine monitoring of the composition and mass concentrations of ambient aerosol," Aerosol Science and Technology, vol. 45, no. 7, pp. 780-794, 2011.

[16] A. Reff, S. I. Eberly, and P. V. Bhave, "Receptor modeling of ambient particulate matter data using positive matrix factorization: review of existing methods," Journal of the Air \& Waste Management Association, vol. 57, no. 2, pp. 146-154, 2007.

[17] Q. Zhang, J. L. Jimenez, M. R. Canagaratna et al., "Understanding atmospheric organic aerosols via factor analysis of aerosol mass spectrometry: a review," Analytical and Bioanalytical Chemistry, vol. 401, no. 10, pp. 3045-3067, 2011.

[18] M. Crippa, F. Canonaco, V. A. Lanz et al., "Organic aerosol components derived from 25 AMS data sets across Europe using a consistent ME-2 based source apportionment approach," Atmospheric Chemistry and Physics, vol. 14, no. 12, pp. 6159-6176, 2014.

[19] M. Chin, T. Diehl, O. Dubovik et al., "Light absorption by pollution, dust, and biomass burning aerosols: a global model study and evaluation with AERONET measurements," Annales Geophysicae, vol. 27, no. 9, pp. 3439-3464, 2009.

[20] A. M. Middlebrook, R. Bahreini, J. L. Jimenez, and M. R. Canagaratna, "Evaluation of composition-dependent collection efficiencies for the aerodyne aerosol mass spectrometer using field data," Aerosol Science and Technology, vol. 46, no. 3, pp. 258-271, 2012.

[21] P. G. Gormley and M. Kennedy, "Diffusion from a stream flowing through a cylindrical tube," Proceedings of the Royal Irish Academy. Section A: Mathematical and Physical Sciences, vol. 52, pp. 163-169, 1948.

[22] M. Collaud Coen, E. Weingartner, A. Apituley et al., "Minimizing light absorption measurement artifacts of the Aethalometer: evaluation of five correction algorithms," Atmospheric Measurement Techniques, vol. 3, no. 2, pp. 457-474, 2010.

[23] A. Virkkula, T. Mäkelä, R. Hillamo et al., "A simple procedure for correcting loading effects of Aethalometer data," Journal of the Air \& Waste Management Association, vol. 57, no. 10, pp. 1214-1222, 2007.
[24] E. Weingartner, H. Saathoff, M. Schnaiter, N. Streit, B. Bitnar, and U. Baltensperger, "Absorption of light by soot particles: determination of the absorption coefficient by means of aethalometers," Journal of Aerosol Science, vol. 34, no. 10, pp. 1445-1463, 2003.

[25] J. Sandradewi, A. S. H. Prévôt, E. Weingartner, R. Schmidhauser, M. Gysel, and U. Baltensperger, "A study of wood burning and traffic aerosols in an Alpine valley using a multi-wavelength Aethalometer," Atmospheric Environment, vol. 42, no. 1, pp. 101-112, 2008.

[26] B. L. Zhuang, T. J. Wang, J. Liu et al., “Absorption coefficient of urban aerosol in Nanjing, west Yangtze River Delta, China," Atmospheric Chemistry and Physics, vol. 15, no. 23, pp. 13633-13646, 2015.

[27] C. D. Cappa, K. R. Kolesar, X. Zhang et al., "Understanding the optical properties of ambient sub- and supermicron particulate matter: results from the CARES 2010 field study in northern California," Atmospheric Chemistry and Physics, vol. 16, no. 10, pp. 6511-6535, 2016.

[28] C. Liu, C. E. Chung, Y. Yin, and M. Schnaiter, "The absorption Ångström exponent of black carbon: from numerical aspects," Atmospheric Chemistry Physics, vol. 18, no. 9, pp. 6259-6273, 2018.

[29] P. B. Russell, R. W. Bergstrom, Y. Shinozuka et al., "Absorption angstrom exponent in AERONET and related data as an indicator of aerosol composition," Atmospheric Chemistry and Physics, vol. 10, no. 3, pp. 1155-1169, 2010.

[30] P. Zotter, H. Herich, M. Gysel et al., "Evaluation of the absorption Ångström exponents for traffic and wood burning in the Aethalometer-based source apportionment using radiocarbon measurements of ambient aerosol," Atmospheric Chemistry and Physics, vol. 17, no. 6, pp. 4229-4249, 2017.

[31] M. Crippa, P. F. Decarlo, J. G. Slowik et al., "Wintertime aerosol chemical composition and source apportionment of the organic fraction in the metropolitan area of Paris," Atmospheric Chemistry and Physics, vol. 13, no. 2, pp. 961-981, 2013.

[32] M. Crippa, F. Canonaco, J. G. Slowik et al., "Primary and secondary organic aerosol origin by combined gas-particle phase source apportionment," Atmospheric Chemistry and Physics, vol. 13, no. 2, pp. 8411-8426, 2013.

[33] I. M. Ulbrich, M. R. Canagaratna, Q. Zhang, D. R. Worsnop, and J. L. Jimenez, "Interpretation of organic components from positive matrix factorization of aerosol mass spectrometric data," Atmospheric Chemistry and Physics, vol. 9, no. 9, pp. 2891-2918, 2009.

[34] P. Paatero, S. Eberly, S. G. Brown, and G. A. Norris, "Methods for estimating uncertainty in factor analytic solutions," Atmospheric Measurement Techniques, vol. 7, no. 3, pp. 781797, 2014.

[35] P. Massoli, E. C. Fortner, M. R. Canagaratna et al., "Pollution gradients and chemical characterization of particulate matter from vehicular traffic near major roadways: results from the 2009 Queens College Air Quality Study in NYC," Aerosol Science and Technology, vol. 46, no. 11, pp. 12011218, 2012.

[36] A. Bougiatioti, I. Stavroulas, E. Kostenidou et al., "Processing of biomass-burning aerosol in the eastern Mediterranean during summertime," Atmospheric Chemistry and Physics, vol. 14, no. 9, pp. 4793-4807, 2014.

[37] Q. H. Hu, Z. Q. Xie, X. M. Wang, H. Kang, and P. Zhang, "Levoglucosan indicates high levels of biomass burning 
aerosols over oceans from the Arctic to Antarctic," Scientific Reports, vol. 3, no. 1, pp. 1-7, 2013.

[38] S. Gilardoni, P. Massoli, M. Paglione et al., "Direct observation of aqueous secondary organic aerosol from biomassburning emissions," Proceedings of the National Academy of Sciences, vol. 113, no. 36, pp. 10013-10018, 2016.

[39] L. Q. Hao, A. Kortelainen, S. Romakkaniemi et al., "Atmospheric submicron aerosol composition and particulate organic nitrate formation in a boreal forestland-urban mixed region," Atmospheric Chemistry and Physics, vol. 14, no. 24, pp. 13483-13495, 2014.

[40] J. Pauraitè, G. Mordas, S. Byčenkienè, and V. Ulevicius, "Spatial and temporal analysis of organic and black carbon mass concentrations in Lithuania," Atmosphere, vol. 6, no. 8, pp. 1229-1242, 2015.

[41] S. Byčenkiene, K. Plauškaite, V. Dudoitis, and V. Ulevicius, "Urban background levels of particle number concentration and sources in Vilnius, Lithuania," Atmospheric Research, vol. 143, pp. 279-292, 2014.

[42] S. Nepomuceno Pereira, F. Wagner, and A. M. Silva, "Multiyear measurements of the aerosol absorption coefficient near the surface in a small-sized urban area in Portugal," Advances in Meteorology, vol. 2014, pp. 1-8, 2014.

[43] S. Segura, V. Estellés, G. Titos et al., "Determination and analysis of in situ spectral aerosol optical properties by a multi-instrumental approach," Atmospheric Measurement Techniques, vol. 7, no. 8, pp. 2373-2387, 2014.

[44] B. Zhuang, T. Wang, J. Liu et al., "The surface aerosol optical properties in the urban area of Nanjing, west Yangtze River Delta, China," Atmospheric Chemistry and Physics, vol. 17, no. 2, pp. 1143-1160, 2017.

[45] J. Wang, A. Virkkula, Y. Gao et al., "Observations of aerosol optical properties at a coastal site in Hong Kong, South China," Atmospheric Chemistry and Physics, vol. 17, no. 4, pp. 2653-2671, 2017.

[46] O. Favez, I. El Haddad, C. Piot et al., "Inter-comparison of source apportionment models for the estimation of wood burning aerosols during wintertime in an Alpine city (Grenoble, France)," Atmospheric Chemistry and Physics, vol. 10, no. 12, pp. 5295-5314, 2010.

[47] D. A. Lack and J. M. Langridge, "On the attribution of black and brown carbon light absorption using the Ångström exponent," Atmospheric Chemistry and Physics, vol. 13, no. 20, pp. 10535-10543, 2013.

[48] D. a. Lack and C. D. Cappa, "Impact of brown and clear carbon on light absorption enhancement, single scatter albedo and absorption wavelength dependence of black carbon," Atmospheric Chemistry and Physics, vol. 10, no. 9, pp. 42074220, 2010.

[49] F. Costabile, F. Barnaba, F. Angelini, and G. P. Gobbi, "Identification of key aerosol populations through their size and composition resolved spectral scattering and absorption," Atmospheric Chemistry and Physics, vol. 13, no. 5, pp. 24552470, 2013.

[50] R. Li, Y. Hu, L. Li, H. Fu, and J. Chen, "Real-time aerosol optical properties, morphology and mixing states under clear, haze and fog episodes in the summer of urban Beijing," Atmospheric Chemistry and Physics, vol. 17, no. 8, pp. 5079-5093, 2017.

[51] M. Zhang, Y. Ma, W. Gong, and Z. Zhu, "Aerosol optical properties of a haze episode in Wuhan based on ground-based and satellite observations," Atmosphere, vol. 5, no. 4, pp. 699-719, 2014.

[52] P. Yan, J. Tang, J. Huang et al., "The measurement of aerosol optical properties at a rural site in Northern China,"
Atmospheric Chemistry and Physics, vol. 8, no. 8, pp. 22292242, 2008.

[53] D. Goto, K. V. S. Badarinath, T. Takemura, and T. Nakajima, "Simulation of aerosol optical properties over a tropical urban site in India using a global model and its comparison with ground measurements," Annales Geophysicae, vol. 29, no. 5, pp. 955-963, 2011.

[54] T. C. Bond and R. W. Bergstrom, "Light absorption by carbonaceous particles: an investigative review," Aerosol Science and Technology, vol. 40, no. 1, pp. 27-67, 2006. 

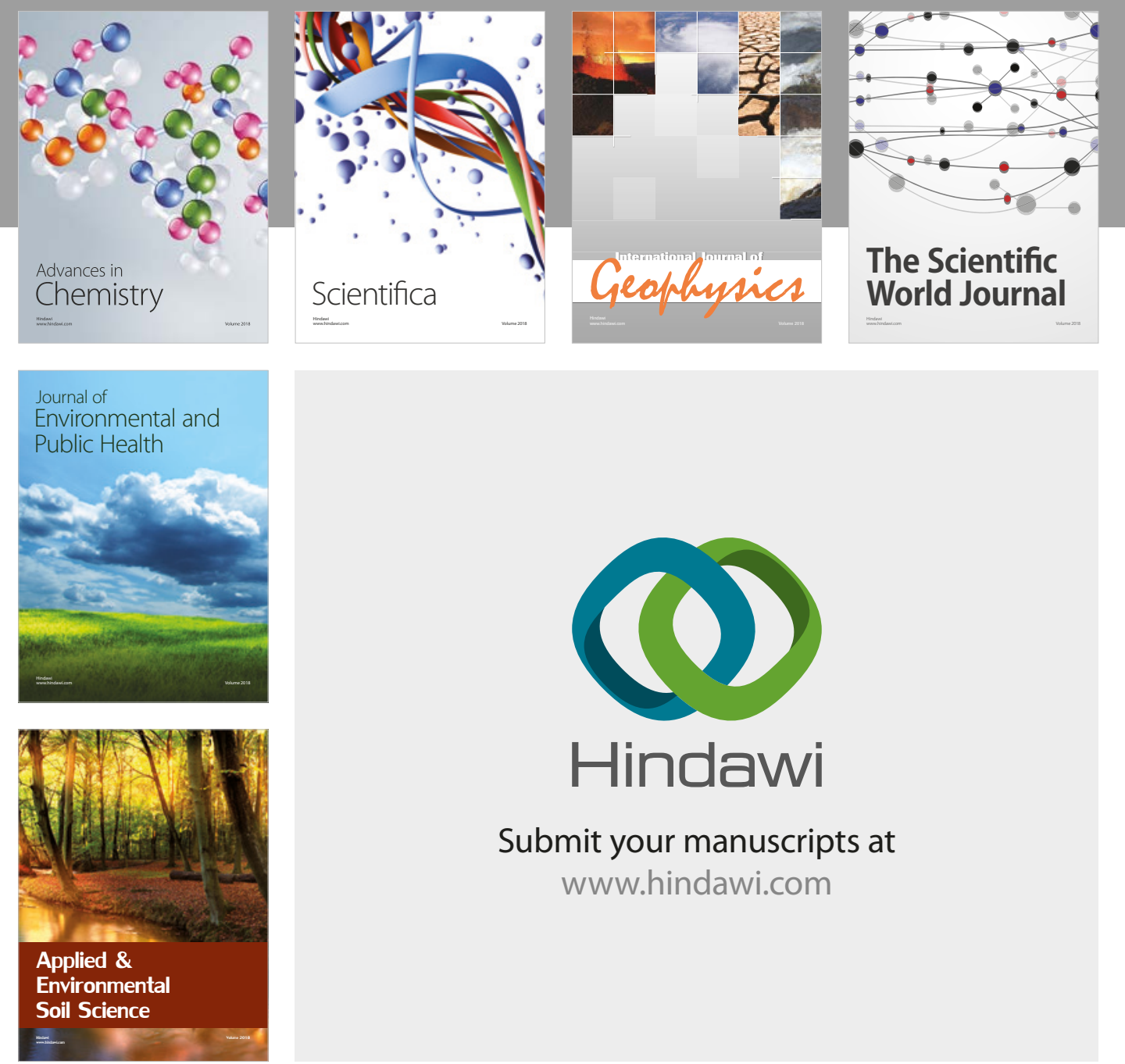

The Scientific

\section{World Journal}
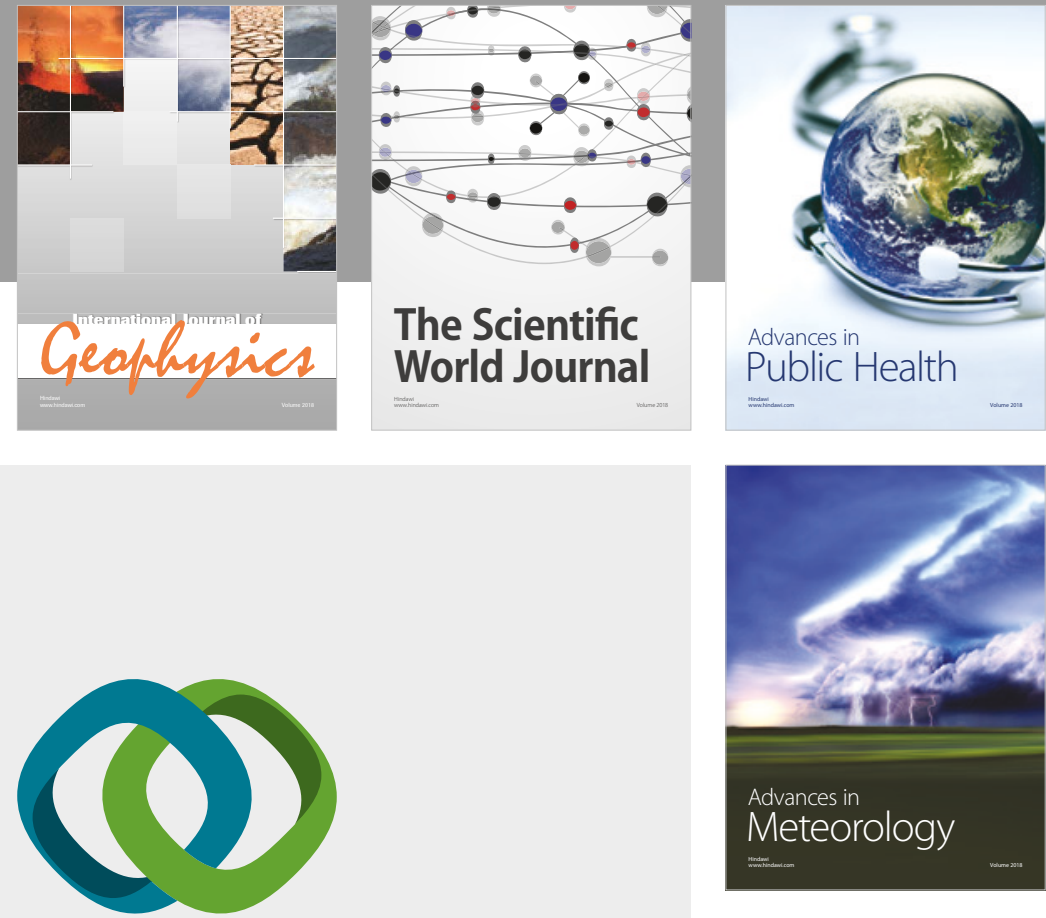

Advan

Public Health

\section{Hindawi}

Submit your manuscripts at

www.hindawi.com
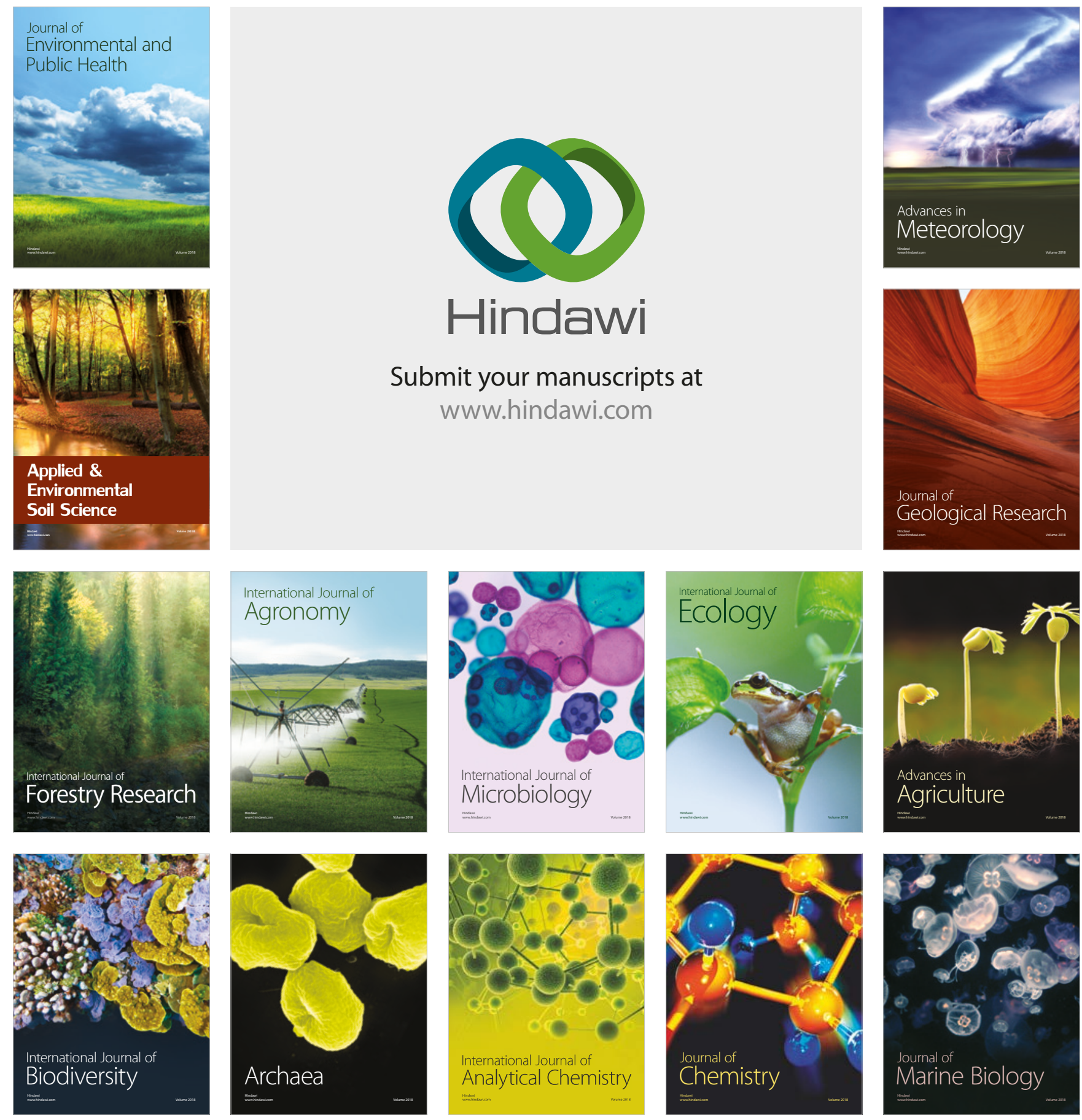